\title{
Psychological well-being and gender difference in alcohol and substance use among people living with HIV/AIDS
}

\author{
Adetunji Obadeji1,2, Lateef O. Oluwole ${ }^{1,2}$, Banji Kumolalo ${ }^{2}$, Adedotun S. Ajiboye ${ }^{2}$ \\ ${ }^{1}$ Department of Psychiatry, College of Medicine, Ekiti State University, Nigeria \\ ${ }^{2}$ Department of Psychiatry, Ekiti State University Teaching Hospital, Ado-Ekiti, Ekiti State, Nigeria
}

\begin{abstract}
Introduction: Amidst unfavorable effects of alcohol and other substances on the course and outcomes of human immunodeficiency virus (HIV) infection, this study aimed at identifying patterns of alcohol and substance usage and their association with gender and presence of psychological distress among people living with HIV/acquired immunodeficiency syndrome (AIDS) (PLWHA).

Material and methods: Using a cross-sectional survey, questionnaires with socio-demographic variables, Kessler psychological distress (K-10), and the condensed alcohol, smoking, and substance involvement screening test (ASSIST) were administered to PLWHA attending HIV clinic at the State University Teaching Hospital, Ado-Ekiti, Nigeria. Lifetime and current substance use as well as levels of risky use of alcohol and other substances were determined, and their relationship with gender and psychological distress were verified using bivariate statistics.

Results: Among 297 participants, the majority were females (72.0\%), with mean age of 37.49 years $(\mathrm{SD}=10.02)$. Lifetime and current prevalence were alcohol $62.6 \%$ and $37.0 \%$; cannabis $6.1 \%$ and $2.7 \%$; nicotine $14.8 \%$ and $6.1 \%$; and sedatives $43.1 \%$ and $15.4 \%$, respectively. Males were more likely to drink alcohol, use cannabis, and smoke cigarettes than their female counterparts $(p<0.001)$. Those who were current sedatives users were more likely to be experiencing psychological distress $(p=0.023)$.

Conclusions: Despite the negative effect of alcohol on the course and outcomes of HIV infection, a higher proportion of the participants had a history of lifetime and current alcohol and other substance use, with the majority of current substance users being a moderate- to high-risk users. Interventions aimed at reducing excessive substance use are needed to optimize treatment outcomes.
\end{abstract}

HIV AIDS Rev 2021; 20, 2: 114-120

DOI: https://doi.org/10.5114/hivar.2021.107238

Key words: gender, psychological distress, substance use, HIV/AIDS, alcohol.

\section{Introduction}

Alcohol and drug use are universal phenomenon. Globally, alcohol use disorders constitute the most prevalent of all substance use disorders with over 100 million estimated cases in 2016 , followed by cannabis dependence with over
22 million cases [1]. The use of alcohol alone accounts for $42 \%$ of all disability adjusted life years (DALYs), while $13 \%$ of all DALYs were attributable to drug use. Across the globe, the burden of disease attributable to alcohol and other drug use vary substantially, with the greater part of this burden resulting from alcohol and drug use on other health out-

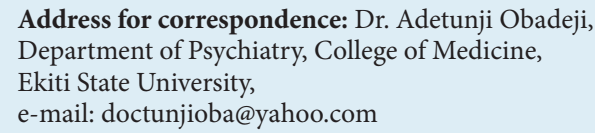

\section{Article history:}

Received: 19.04 .2020

Received in revised form: 09.09.2020

Accepted: 08.10.2020

Available online: 30.06 .2021
International Journal of HIV-Related Problems

HIV \& AIDS

R e vi e w 
comes [2-4]. The use of alcohol and other substances have a deleterious effect, not just on the health of users but also on other segments of the society. The use of alcohol, for example, increases the risk of accident and self-harm as well as the risk of contracting sexually transmitted diseases, including human immunodeficiency virus (HIV) $[5,6]$.

There is a strong link between alcohol, drug use, and HIV epidemics. Studies have consistently shown an association between alcohol use and sexual risks for HIV infection [6-8]. Among people who drink alcohol, greater sexual risks are associated with higher quantity of alcohol than does the frequency of drinking. The relationship between alcohol and sexual risk behavior is stronger among men than women, whose sexual risks are often associated with their male sex partners' level of drinking [6]. Similarly, the use of tobacco and other substances increases the risk of sexual behavior, and have profound effect on the course and prognosis of HIV among infected individuals [9-12], including adherence to antiretroviral therapy $[10,12]$. Alcohol use has negative effects on HIV disease progression through several mechanisms, such as reduction of the ability to practice safer sex, its effect on viral replication, host immunity, treatment efficacy, increased risk of side effects of medications, and change of pharmacokinetics of prescribed drugs $[9,13-16]$.

Despite the negative effects of alcohol and other substances use on acquired immunodeficiency syndrome (AIDS), most studies continue to report a high-rate of alcohol and other substances use among PLWHA [7, 12, 17]. In a sample of people receiving care for HIV in the United State, for example, half of the study population reported illicit drug use in the preceding 12 months, with over 10 percent meeting the criteria for drug dependence [18]. In a similar study, the rate of heavy drinking was nearly twice as high among HIV-infected individuals compared with general population [19]. Also, studies investigating alcohol and illicit drugs use among PLWHA had reported a higher prevalence, from about a quarter to half reporting alcohol use in Brazil $[12,20]$ to nearly $32 \%$ to $42 \%$ with alcohol use disorders in Ethiopia and Nepal $[10,21,22]$, with about 5 percent reporting illicit drugs use $[12,20]$. Factors, which were found to be associated with a substance use among this population included being male, having low education, low income, smoking, poor social support, being medication non-adherent, and using intravenous or inhalation drugs $[20,21,23,24]$.

In Nigeria on the other hand, varying rates of psychoactive substances had been reported, from a lifetime alcohol use of $84.8 \%$ to sedatives use of $21.03 \%$ [23], with alcoholrelated problems of $39.4 \%$ [25] and current use of psychoactive substances of $21.7 \%$, of which $19.3 \%$ were alcohol users [24].

Alcohol and drug abuse remain a challenge among people living with HIV/AIDS, not just in limiting the spread, but also in determining the course and prognosis of the disease. Despite this fact, few studies have investigated the prevalence and pattern of use of alcohol and other substances among PLWHA as well as the factors influencing these aspects in Nigeria. The objective of this study was to deter- mine patterns of alcohol and other substance use and their relationship with gender and psychological distress among a population of PLWHA in Nigeria.

\section{Material and methods}

\section{Study setting and design}

This study was a cross-sectional survey, conducted among PLWHA attending the Ekiti State University Teaching Hospital, Ado-Ekiti, Nigeria. The state-owned tertiary health institution provides counselling and care to PLWHA in the state and neighboring states.

\section{Study population and eligibility}

Two hundred and ninety-seven participants were recruited for the study through random sampling of patients receiving care at the HIV/AIDS clinic and counselling unit of the Ekiti State University Teaching Hospital, Ado-Ekiti in South-West Nigeria. At the time of the study, the clinic had about 890 eligible participants registered at the clinic who were on follow-up. The minimum sample size was determined with an online sample simple size calculator with the following assumptions: eligible target population of 890 , standard normal distribution with $95 \%$ confidence interval (CI) Z score of 1.96, and tolerable margin of error or level of precision of $d=0.05$. Ten percent attrition was added to provide a final sample size of 295. Study eligibility included 18 years of age or older, confirmed HIV-infected sero-status diagnosed not less than six months prior to time of the study, relatively mentally stable with the ability to provide informed consent and speak English or Yoruba, and currently receiving HIV care at the HIV clinic and counselling unit of the teaching hospital.

\section{Measures}

Socio-demographic characteristics of the respondents were obtained using a pre-tested socio-demographic questionnaire with information, such as age, marital status, level of education, employment status, and religion. History of alcohol and drug use were acquired using the condensed alcohol, smoking, and substance involvement screening test (ASSIST) [26], and psychological distress was obtained using Kessler psychological distress scale (K-10) [27].

The K-10 measures the presence of psychological distress in the last four weeks. It consists of 10 questions about emotional states, each with a five-level response scale. Each item is scored on a Likert scale of one to five (one meaning 'none of the time' to five meaning 'all of the time'). In this study, the participants' scores were dichotomized into two, i.e., those with K-10 score of 10-19 (patients without psychological distress) and those scoring 20 and above (patients with significant psychological distress).

Alcohol, smoking, and substance involvement screening test (ASSIST) used by the World Health Organization 
Table 1. Socio-demographic characteristics of the participants

\begin{tabular}{|c|c|}
\hline Variables & $n(\%)$ \\
\hline \multicolumn{2}{|l|}{ Age group } \\
\hline $18-39$ & $161(54.2)$ \\
\hline$\geq 40$ & $136(45.8)$ \\
\hline \multicolumn{2}{|l|}{ Gender } \\
\hline Males & $77(25.9)$ \\
\hline Females & $220(74.1)$ \\
\hline \multicolumn{2}{|l|}{ Level of education } \\
\hline None & $11(3.6)$ \\
\hline Primary & $43(14.5)$ \\
\hline Secondary & $108(36.4)$ \\
\hline Tertiary & $135(45.5)$ \\
\hline \multicolumn{2}{|l|}{ Marital status } \\
\hline Single & $38(12.8)$ \\
\hline Married & $207(69.7)$ \\
\hline Separated/divorced & $20(6.7)$ \\
\hline Widowed & $32(10.8)$ \\
\hline \multicolumn{2}{|l|}{ Religion } \\
\hline Christianity & $259(87.2)$ \\
\hline Islam & $37(12.5)$ \\
\hline Other & $1(0.3)$ \\
\hline \multicolumn{2}{|l|}{ Employment status } \\
\hline Employed & $253(85.2)$ \\
\hline Unemployment & $44(14.8)$ \\
\hline Students & $9(3.0)$ \\
\hline \multicolumn{2}{|l|}{ Nature of employment } \\
\hline Self-employed & $179(70.8)$ \\
\hline Private organization & $11(4.3)$ \\
\hline Public organization & $63(24.9)$ \\
\hline
\end{tabular}

Table 2. Pattern of use of alcohol and other substances

\begin{tabular}{l|c|c}
\hline Substances & $\begin{array}{c}\text { Lifetime use } \\
\boldsymbol{n}(\%)\end{array}$ & $\begin{array}{c}\text { Current use } \\
\boldsymbol{n}(\%)\end{array}$ \\
\hline Alcohol & $186(62.6)$ & $110(37.0)$ \\
\hline Cannabis & $18(6.1)$ & $8(2.7)$ \\
\hline Nicotine & $44(14.8)$ & $18(6.1)$ \\
\hline Sedatives & $128(43.1)$ & $45(15.2)$ \\
\hline Other opiates & $25(8.4)$ & $14(4.7)$ \\
\hline Cocaine & $1(0.3)$ & $0(0.0)$ \\
\hline Heroine & $0(0.0)$ & $0(0.0)$ \\
\hline Injection drug use & $0(0.0)$ & $0(0.0)$ \\
\hline
\end{tabular}

(WHO) was applied to evaluate all levels of problems or risky substance use among the participants [27]. ASSIST comprises eight questions regarding alcohol, tobacco, cannabis, amphetamine-type stimulants (including ecstasy), cocaine, inhalants, sedatives hypnotics, hallucinogens, opioids, and other substances. A risk score was provided for the four major substances of abuse, and scores were grouped into "low-risk", "moderate-risk", and "high-risk". According to the ASSIST manual, a score of 0-10 is regarded as low-risk, 11-26 as moderate-risk, and 27+ as high-risk. The risk score determines the level of intervention needed, either brief or brief intervention plus referral to a treatment center. ASSIST shows high specificities (50-96\%) and sensitivities (54-97\%) for most of the substances [28, 29].

\section{Ethical considerations}

The study protocol was approved by the Institutional Review Board of the Ekiti State University Hospital, Ado-Ekiti. Written informed consent was sought and obtained from all participants of the study.

\section{Data analysis}

Statistical analysis was performed using Statistical Package for Social Sciences (version 25.0. IBM Inc., Chicago, Illinois, USA). Bivariate analysis was used to determine the association between psychological distress, gender, and both drug and alcohol use variables, using Pearson's $\chi^{2}$ statistics, with Fishers exact, wherever appropriate. The level of precision was set at $95 \%$ confidence interval (CI) and the level of significance was $p=0.05$.

\section{Results}

\section{General measures}

Two hundred and ninety-seven participants completed socio-demographic, and ASSIST and K-10 questionnaires. Their mean age and the mean duration of diagnosis were 37.49 years, standard deviation $(\mathrm{SD})=10.02$ and 4.18 years $(\mathrm{SD}=3.41)$, respectively. The participants were mostly females (74.1\%), married (69.7\%), employed (85.2\%), and with more than six years of education (81.9\%). Other demographic variables are shown in Table 1.

\section{Alcohol and substance use patterns}

Nearly two-thirds (62.6\%) of the study participants reported lifetime use of alcohol, and about a third (37.0\%) of these had a history of recent alcohol use in the past three months. Recent alcohol users were classified as low- (20.0\%), moderate- (43.6\%), and high-risk users (36.4\%). Forty-four (14.8\%) and $18(6.1 \%)$ of the participants reported lifetime and recent use of tobacco, respectively. None of the participants reported injection drug use. The patterns of other substances are presented in Table 2. 


\section{Alcohol and substance use risk}

Figure 1 shows the level of risk of four major substances used by the participants in this study. The majority of current alcohol users $(80.0 \%)$ were moderate- to high-risk users, while the majority of cannabis users were low- to moderate-risk users. Similar results were for sedatives and nicotine users.

\section{Relationship between gender and substance use}

Table 3 shows the relationship between gender and substance use. Significantly, men were more likely to have a history of lifetime alcohol use (OR $=1.70$; $95 \%$ CI: 1.08 $2.67 \%)$ compared with women $(\mathrm{OR}=0.85$; 95\% CI: 0.74 $0.96 \%), p=0.016$, and current alcohol use $(\mathrm{OR}=2.04 ; 95 \%$ CI: $1.39-2.99 \%)$ compared with their female counterparts $(\mathrm{OR}=0.76$; 95\% CI: 0.65-0.88\%), $p<0.001$. With the exception of opiates and sedatives, where there was no gender difference in the rate of use, significantly, men were more likely to present with a lifetime history of cannabis use $(\mathrm{OR}=4.06$; 95\% CI: 3.09-5.36\%) compared with females $(\mathrm{OR}=0.14$; 95\% CI: $0.04-0.53 \%)$, and recent history of cannabis use (OR $=4.10$; 95\% CI: 3.09-5.36\%), $p<0.001$. Similarly, men were more likely to have a lifetime history nicotine use $(\mathrm{OR}=5.32 ; 95 \% \mathrm{CI}: 3.89-7.27 \%)$ compared with women $(\mathrm{OR}=0.19 ; 95 \% \mathrm{CI}: 0.10-0.37 \%)$, and current nicotine use $(\mathrm{OR}=4.46 ; 95 \% \mathrm{CI}: 3.48-5.73 \%)$ compared with females $(\mathrm{OR}=0.07 ; 95 \%$ CI: $0.01-0.45 \%), p<0.001$.

\section{Relationship between substance use and psychological distress}

Table 4 indicates the relationship of substance use and psychological distress. With the exception of sedatives, where higher proportion of current users compared with those who were not $(\mathrm{OR}=0.97 ; 95 \% \mathrm{CI}: 0.24-0.92 \%)$ reported significant psychological distress $(p=0.023)$, there was no statistically significant association between other drug variables and psychological distress $(p>0.05)$. Other findings are shown in Table 4.

\section{Discussion}

Although studies have shown the harmful effect of alcohol and other substances use on the prevention, course, and prognosis of HIV/AIDS in PLWHA, quite an appreciable number of PLWHA still drink alcohol and use other drugs. The lifetime and current prevalence of alcohol and nicotine use found among this population were higher than national rates, including alcohol (lifetime, 39\%; current use, 24.5\%), tobacco (lifetime, 12.2\%; current use, 5.3\%), and likewise current cannabis use (1.8\%), but comparable with lifetime marijuana use (6.6\%) [30]. This suggests that PLWHA are at greater risk of alcohol, nicotine, and cannabis use than the general population. Greater attention needs to be paid

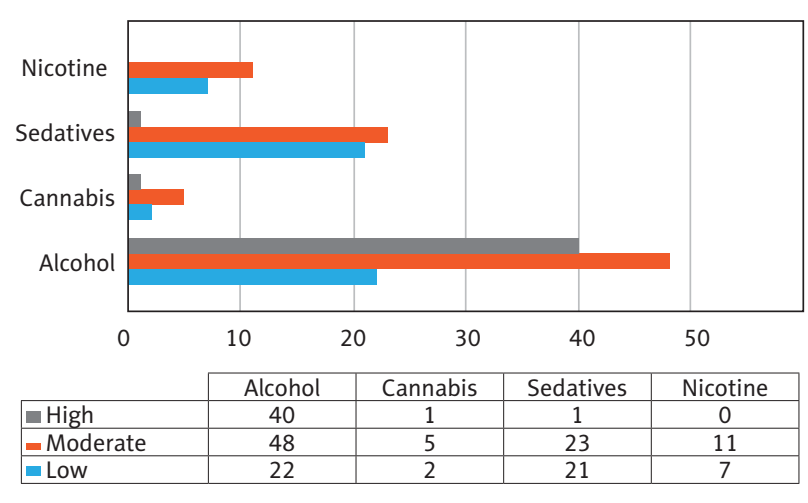

Figure 1. Alcohol and substance use risk

Table 3. Relationship between gender and drug use Drug patterns Males, $\mathrm{n}(\%) \quad$ Females, $n(\%) \quad p$-value Lifetime alcohol use

\begin{tabular}{l|c|c|c}
\hline Yes & $57(74.0)$ & $129(58.6)$ & \multirow{2}{*}{0.016} \\
\cline { 1 - 3 } No & $20(26.0)$ & $91(41.4)$ & \\
\hline
\end{tabular}

Current alcohol use

\begin{tabular}{l|c|c|c}
\hline Yes & $42(54.5)$ & $67(30.5)$ & \multirow{2}{*}{$<0.001$} \\
\cline { 1 - 3 } No & $35(45.0)$ & $153(69.5)$ & \\
\hline
\end{tabular}

Lifetime cannabis use

\begin{tabular}{l|c|c|c}
\hline Yes & $16(20.8)$ & $2(0.9)$ & \multirow{2}{*}{$<0.001$} \\
\cline { 1 - 3 } No & $61(79.2)$ & $218(99.1)$ & \\
\hline
\end{tabular}

Current cannabis use

\begin{tabular}{l|c|c|c}
\hline Yes & $8(10.4)$ & $0(0.0)$ & \multirow{2}{*}{$<0.001$} \\
\cline { 1 - 3 } No & $69(89.9)$ & $220(100.0)$ & \\
\hline
\end{tabular}

Lifetime nicotine use

\begin{tabular}{l|c|c|c}
\hline Yes & $37(48.1)$ & $7(3.2)$ & \multirow{2}{*}{$<0.001$} \\
\cline { 1 - 3 } No & $40(51.9)$ & $213(84.2)$ & \\
\cline { 1 - 2 }
\end{tabular}

Current nicotine use

\begin{tabular}{l|c|c|c}
\hline Yes & $18(23.4)$ & $0(0.0)$ & \multirow{2}{*}{$<0.001$} \\
\cline { 1 - 3 } No & $59(76.6)$ & $220(100.0)$ & \\
\hline
\end{tabular}

Lifetime sedative use

\begin{tabular}{l|l|l|l}
\hline Yes & $28(36.4)$ & $100(45.5)$ & \multirow{2}{*}{0.183} \\
\cline { 1 - 3 } No & $49(63.6)$ & $120(54.5)$ & \\
\hline
\end{tabular}

Current sedative use

\begin{tabular}{l|c|c|c}
\hline Yes & $9(11.7)$ & $36(16.6)$ & \multirow{2}{*}{0.325} \\
\cline { 1 - 3 } No & $68(88.3)$ & $184(83.4)$ & \\
\hline
\end{tabular}

\begin{tabular}{|c|c|c|c|}
\hline \multicolumn{4}{|c|}{ Lifetime opiate use } \\
\hline Yes & 9 (11.7) & $16(8.4)$ & \multirow{2}{*}{0.230} \\
\hline No & $68(88.3)$ & 204 (91.6) & \\
\hline
\end{tabular}

Current opiate use

\begin{tabular}{l|c|c|c}
\hline Yes & $5(6.5)$ & $9(4.1)$ & \multirow{2}{*}{0.392} \\
\cline { 1 - 3 } No & $72(93.5)$ & $211(95.9)$ & \\
\hline
\end{tabular}


Table 4. Relationship between substance use and psychological distress

\begin{tabular}{|c|c|c|c|c|}
\hline \multirow{2}{*}{ Substances use variables } & \multicolumn{2}{|c|}{ Psychological distress } & \multicolumn{2}{|c|}{ Statistics } \\
\hline & No & Yes & OR $(95 \% \mathrm{Cl})$ & $p$-value \\
\hline \multicolumn{5}{|l|}{ Lifetime alcohol use } \\
\hline Yes & $138(74.2)$ & $48(25.8)$ & \multirow{2}{*}{$1.07(0.63-1.81)$} & \multirow{2}{*}{0.892} \\
\hline No & $81(73.8)$ & $30(29.2)$ & & \\
\hline \multicolumn{5}{|l|}{ Current alcohol use } \\
\hline Yes & $80(73.4)$ & $29(26.6)$ & \multirow{2}{*}{$0.92(0.54-1.57)$} & \multirow{2}{*}{1.000} \\
\hline No & $139(73.9)$ & $49(26.1)$ & & \\
\hline \multicolumn{5}{|l|}{ Lifetime cannabis use } \\
\hline Yes & $11(61.1)$ & $7(38.1)$ & \multirow{2}{*}{$0.54(0.20-1.44)$} & \multirow{2}{*}{0.289} \\
\hline No & $208(74.6)$ & $71(25.4)$ & & \\
\hline \multicolumn{5}{|l|}{ Current cannabis use } \\
\hline Yes & $4(50.0)$ & $4(50.0)$ & \multirow{2}{*}{$0.34(0.08-1.41)$} & \multirow{2}{*}{0.213} \\
\hline No & $215(74.4)$ & $74(25.6)$ & & \\
\hline \multicolumn{5}{|l|}{ Lifetime nicotine use } \\
\hline Yes & $30(68.2)$ & $14(31.8)$ & \multirow{2}{*}{$0.73(0.362-1.45)$} & \multirow{2}{*}{0.458} \\
\hline No & $189(74.7)$ & $64(25.3)$ & & \\
\hline \multicolumn{5}{|l|}{ Current nicotine use } \\
\hline Yes & $11(61.1)$ & $7(38.9)$ & \multirow{2}{*}{$0.46(0.18-1.20)$} & \multirow{2}{*}{0.105} \\
\hline No & $208(74.6)$ & $71(25.4)$ & & \\
\hline \multicolumn{5}{|l|}{ Lifetime sedative use } \\
\hline Yes & $93(72.7)$ & $35(27.3)$ & \multirow{2}{*}{$0.92(0.55-1.55)$} & \multirow{2}{*}{0.790} \\
\hline No & $208(74.6)$ & $43(25.4)$ & & \\
\hline \multicolumn{5}{|l|}{ Current sedative use } \\
\hline Yes & $27(60.0)$ & $18(40.0)$ & \multirow{2}{*}{$0.97(0.24-0.92)$} & \multirow{2}{*}{0.023} \\
\hline No & $192(76.2)$ & $60(23.8)$ & & \\
\hline \multicolumn{5}{|l|}{ Lifetime opiate } \\
\hline Yes & $13(52.0)$ & $12(48.0)$ & \multirow{2}{*}{$0.35(0.15-0.80)$} & \multirow{2}{*}{0.010} \\
\hline No & $266(75.7)$ & $66(24.3)$ & & \\
\hline
\end{tabular}

Cl - confidence interval, OR - odds ratio

to PLWHA in order to reduce the negative impact of these substances on the prevention, course, and prognosis of HIV infection.

In this study, nearly two-thirds of the participants had a history of lifetime use of alcohol. Though high, the lifetime prevalence reported in this study was lower than $84.8 \%$ reported by Koyejo and Gbiri in Lagos, Nigeria, among similar population [23]. The background setting where this study was conducted may explain the difference. Similar to other findings, about a third of the participants of this study still used alcohol within the preceding 3 months [2, 20, 25]. Compared with the general population $[30,31]$ and the negative effect of alcohol on the prevention and course of HIV infection, the proportion of PLWHA that was using alcohol was still substantial. The use of alcohol has been reported as an important risk factor in the transmission of HIV infection, besides its negative effect on the course of HIV/AIDS
$[11,12,20]$. As noted earlier, people who drink alcohol are more likely to engage in risky sexual behavior than people who do not. The relatively high prevalence of current alcohol use, with the majority being moderate to high drinkers, necessitates the need to incorporate programs aiming at minimizing alcohol use among PLWHA.

In the current study, besides alcohol use, the participants also engaged themself in the use of other substances, such as cigarettes, cannabis, and opiate-like drugs, specifically tramadol and sedatives. Earlier studies had shown an association between alcohol use and other substances, especially cigarettes $[17,23,32]$. People who abuse alcohol are more likely to use other substances. In this study, there was a significant relationship between the use of alcohol and usage of other substances, meaning that a higher proportion of those who use other substances was more likely to use alcohol. Alcohol being the gateway drug may pave the way for 
the use of other psychoactive drugs. The usage of these substances may have an additive negative effect on the course and prognosis of HIV infection. For example, frequent cannabis smoking has been reported as a risk factor for lung disease in HIV-positive men $[32,34]$. This is independent of smoking and CD4+ cell count. Again, the mortality rate was twice as high among smokers with HIV infection than within non-HIV-infected population [35-37]. All these factors necessitate the inclusion of programs aiming at reducing the use of alcohol and other substances among PLWHA.

One interesting finding of this study was the relatively high prevalence of sedative-hypnotic users and significant relationship of this with the presence of psychological distress. This suggests that PLWHA with psychological distress are medicating themselves with sedatives-hypnotics, either to manage psychological symptoms or sleep problems associated with HIV infection. Several psycho-social factors, including interpersonal conflict and psychological disorders, such as anxiety and depression, have been reported to be high among people living with HIV/AIDS [24, 38, 39]. Insomnia is common among people living with HIV/AIDS [40], and relatively high usage of sedatives among those with psychological distress may explain this association. Nevertheless, the use of sedatives by PLWHA has been reported to reduce their quality of life [41]. Contrary to some other studies, our study did not find any significant association between psychological distress and recent use of alcohol or other substances, except sedatives-hypnotics. The use of those substances may be habitual and predate the diagnosis of HIV, rather than a response to psychological distress.

Except for opiates and sedatives, significantly, more males reported higher rates of alcohol and other substances compared with their female counterparts. Over half of the men were current users of alcohol compared with about a third of women. Also, nearly 10 percent of men were current cannabis user as against none of the women. Other studies had reported similar findings among PLWHA [42-45]. This observation may be a reflection of the general population [46]. Culturally, people have some prejudice against women who drink, smoke cigarettes, or cannabis in this environment, and if they do, they may find it difficult to divulge such information. Despite such, a handful number of women still drink alcohol or smoke cigarettes, even in the recent 3 months preceding interview.

\section{Conclusions}

In spite of the adverse effects of alcohol and other substances on the prevention, course, and prognosis of HIV, quite an appreciable number of PLWHA still drinks alcohol and uses other substances. In a bid to prevent transmission and improve the outcomes of treatment of PLWHA, efforts should be taken at reducing the use of alcohol and other substances among PLWHA. Programs aimed at reducing substance use among PLWHA should be incorporated into the management of this population of people in Nigeria and other developing nations. More attention needs to be paid on men and those who reported psychological distress. The study provides background information aiming at developing intervention programs to reduce alcohol and other substance use among PLWHA.

\section{Conflict of interest}

The authors declare no conflict of interest with respect to the research, authorship, and/or publication of this article.

\section{References}

1. GBD 2015 HIV Collaborators. Estimates of global, regional, and national incidence, prevalence, and mortality of HIV, 1980-2015: the Global Burden of Disease Study 2015. Lancet HIV 2016; 3: e361-387.

2. Chander G. Addressing alcohol use in HIV-infected persons. Top Antivir Med 2011; 19: 143-147.

3. Volkow ND, Montaner J. Enhanced HIV testing, treatment, and support for HIV-infected substance users. JAMA 2010; 303: 1423-1424.

4. Wang H, Wolock TM, Carter A, et al. Estimates of global, regional, and national incidence, prevalence, and mortality of HIV, 19802015: the Global Burden of Disease Study 2015. Lancet HIV 2016; 3: e361-387.

5. Jere DL, Norr KF, Bell CC, et al. Substance use and risky sexual behaviors among young men working at a rural roadside market in Malawi. J Assoc Nurses AIDS Care 2017; 28: 250-265.

6. Kalichman SC, Simbayi LC, Kaufman M, Cain D, Jooste S. Alcohol use and sexual risks for HIV/AIDS in sub-Saharan Africa: systematic review of empirical findings. Prev Sci J Soc Prev Res 2007; 8: 141-151.

7. NIDA. Drug and Alcohol Use - A Significant Risk Factor for HIV. 2015 Available from: https://www.drugabuse.gov/related-topics/ trends-statistics/infographics/drug-alcohol-use-significant-risk -factor-hiv (Accessed: 15.10.2019).

8. Baliunas D, Rehm J, Irving H, Shuper P. Alcohol consumption and risk of incident human immunodeficiency virus infection: a metaanalysis. Int J Public Health 2010; 55: 159-166.

9. Pandrea I, Happel KI, Amedee AM, Bagby GJ, Nelson S. Alcohol's role in HIV transmission and disease progression. Alcohol Res Health 2010; 33: 203-218.

10. Pokhrel KN, Pokhrel KG, Neupane SR, Sharma VD. Harmful alcohol drinking among HIV-positive people in Nepal: an overlooked threat to anti-retroviral therapy adherence and health-related quality of life. Glob Health Action 2018; 11: 1441783.

11. Probst C, Parry CDH, Rehm J. HIV/AIDS mortality attributable to alcohol use in South Africa: a comparative risk assessment by socioeconomic status. BMJ Open 2018; 8: e017955.

12. Teixeira C, Dourado MDL, Santos MP, Brites C. Impact of use of alcohol and illicit drugs by AIDS patients on adherence to antiretroviral therapy in Bahia, Brazil. AIDS Res Hum Retroviruses 2013; 29: 799-804.

13. Bryant KJ, Nelson S, Braithwaite RS, Roach D. Integrating HIV/ AIDS and alcohol research. Alcohol Res Health J Natl Inst Alcohol Abuse Alcohol 2010; 33: 167-178.

14. Neuman MG, Schneider M, Nanau RM, Parry C. Alcohol consumption, progression of disease and other comorbidities, and responses to antiretroviral medication in people living with HIV. AIDS Res Treat 2012; 2012: 751827.

15. Schneider M, Chersich M, Temmerman M, Degomme O, Parry CD. The impact of alcohol on HIV prevention and treatment for South Africans in primary healthcare. Curationis 2014; 37: 1137.

16. Town M, Naimi TS, Mokdad AH, Brewer RD. Health care access among U.S. adults who drink alcohol excessively: missed opportunities for prevention. Prev Chronic Dis 2006; 3: A53. 
17. Bultum JA, Yigzaw N, Demeke W, Alemayehu M. Alcohol use disorder and associated factors among human immunodeficiency virus infected patients attending antiretroviral therapy clinic at Bishoftu General Hospital, Oromiya region, Ethiopia. PLoS One 2018; 13: e0189312.

18. Bing EG, Burnam MA, Longshore D, et al. Psychiatric disorders and drug use among human immunodeficiency virus-infected adults in the United States. Arch Gen Psychiatry 2001; 58: 721-728.

19. Galvan FH, Bing EG, Fleishman JA, et al. The prevalence of alcohol consumption and heavy drinking among people with HIV in the United States: results from the HIV Cost and Services Utilization Study. J Stud Alcohol 2002; 63: 179-186.

20. da Silva CM, Mendoza-Sassi RA, da Mota LD, Nader MM, de Martinez AMB. Alcohol use disorders among people living with HIV/ AIDS in Southern Brazil: prevalence, risk factors and biological markers outcomes. BMC Infect Dis 2017; 17: 263.

21. Duko B, Toma A, Abraham Y. Alcohol use disorder and associated factors among individuals living with HIV in Hawassa City, Ethiopia: a facility based cross-sectional study. Subst Abuse Treat Prev Policy 2019; 14: 22.

22. Soboka M, Tesfaye M, Feyissa GT, Hanlon C. Alcohol use disorders and associated factors among people living with HIV who are attending services in south west Ethiopia. BMC Res Notes 2014; 7: 828.

23. Koyejo OM, Gbiri CA. Psychoactive substance use among people living with HIV/AIDS in a tertiary health care centre in South West Nigeria. Niger J Psychiatry 2015; 13: 49-56.

24. Olagunju AT, Adeyemi JD, Erinfolami AR, Aina OF. HIV/AIDS and psychological distress: The experience of outpatients in a West African HIV clinic. HIV AIDS Rev 2012; 11: 31-35.

25. Goar SG, Audu MD, Agbir MT, Dochalson E. Prevalence and socio-demographic correlates of alcohol use disorders among HIV patients. Afr J Drug Alcohol Stud 2011; 10. Available from: https:// www.ajol.info/index.php/ajdas/article/view/72895.

26. WHO ASSIST Working Group. The Alcohol, Smoking and Substance Involvement Screening Test (ASSIST): development, reliability and feasibility. Addict Abingdon Engl 2002; 97: 1183-1194.

27. Kessler RC, Barker PR, Colpe LJ, et al. Screening for serious mental illness in the general population. Arch Gen Psychiatry 2003; 60: 184-189.

28. Humeniuk R, Ali R, Babor TF, et al. Validation of the Alcohol, Smoking and Substance Involvement Screening Test (ASSIST). Addict Abingdon Engl 2008; 103: 1039-1047.

29. Newcombe DA, Humeniuk RE, Ali R. Validation of the World Health Organization Alcohol, Smoking and Substance Involvement Screening Test (ASSIST): report of results from the Australian site. Drug Alcohol Rev 2005; 24: 217-226.

30. Adamson TA, Ogunlesi AO, Morakinyo O, Akinhanmi AO, Onifade PO. Descriptive national survey of substance use in Nigeria. J Addict Res Ther 2015; 6: 234.

31. Lasebikan VO, Ola BA. Prevalence and correlates of alcohol use among a sample of nigerian semirural community dwellers in Nigeria. J Addict 2016; 2016: 2831594.

32. Bhatta DN, Subedi A, Sharma N. Tobacco smoking and alcohol drinking among HIV infected people using antiretroviral therapy. Tob Induc Dis 2018; 16: 16.

33. Wenger DS, Crothers K. Marijuana smoking in men with HIV infection: a cause for concern. EClinicalMedicine 2019; 7: 5-6.

34. Lorenz DR, Uno H, Wolinsky SM, Gabuzda D. Effect of marijuana smoking on pulmonary disease in HIV-infected and uninfected men: a longitudinal cohort study. EClinicalMedicine 2019; 7: 55-64.

35. Ande A, McArthur C, Kumar A, Kumar S. Tobacco smoking effect on HIV-1 pathogenesis: role of cytochrome P450 isozymes. Expert Opin Drug Metab Toxicol 2013; 9: 1453-1464.

36. Helleberg M, Afzal S, Kronborg G, et al. Mortality attributable to smoking among HIV-1-infected individuals: a nationwide, population-based cohort study. Clin Infect Dis 2013; 56: 727-734.
37. Helleberg M, May MT, Ingle SM, et al. Smoking and life expectancy among HIV-infected individuals on antiretroviral therapy in Europe and North America. AIDS Lond Engl 2015; 29: 221-229.

38. Mthembu JC, Mabaso MLH, Khan G, Simbayi LC. Prevalence of psychological distress and its association with socio-demographic and HIV-risk factors in South Africa: Findings of the 2012 HIV prevalence, incidence and behaviour survey. SSM Popul Health 2017; 3: 658-662.

39. Obadeji A, Ogunlesi A, Adebowale T. Prevalence and predictors of depression in people living with HIV/AIDS attending an outpatient clinic in Nigeria. Iran J Psychiatry Behav Sci 2014; 8: 26-31.

40. Omonuwa TS, Goforth HW, Preud'homme X, Krystal AD. The pharmacologic management of insomnia in patients with HIV. J Clin Sleep Med 2009; 5: 251-262.

41. Korthuis PT, Zephyrin LC, Fleishman JA, et al. Health-related quality of life in HIV-infected patients: the role of substance use. AIDS Patient Care STDs 2008; 22: 859-867.

42. Bello B, Moultrie H, Somji A, Chersich MF, Watts C, Delany-Moretlwe S. Alcohol use and sexual risk behaviour among men and women in inner-city Johannesburg, South Africa. BMC Public Health 2017; 17 (Suppl 3): 65-75.

43. Nguyen NPT, Tran BX, Hwang LY, et al. Prevalence of cigarette smoking and associated factors in a large sample of HIV-positive patients receiving antiretroviral therapy in Vietnam. PLoS One 2015; 10: e0118185.

44. Nouaman MN, Vinikoor M, Seydi M, et al. High prevalence of binge drinking among people living with HIV in four African countries. J Int AIDS Soc 2018; 21: e25202.

45. Weinberger AH, Smith PH, Funk AP, Rabin S, Shuter J. Gender differences in tobacco use among persons living with HIV/AIDS: a systematic review and meta-analysis. J Acquir Immune Defic Syndr 2017; 74: 439-453.

46. Lasebikan VO, Ayinde O, Odunleye M, Adeyefa B, Adepoju S, Fakunle S. Prevalence of alcohol consumption and alcohol use disorders among outdoor drinkers in public open places in Nigeria. BMC Public Health 2018; 18: 400. 